\title{
Understanding Failure Modes of NSF/ANSI 53 Lead-Certified Point- of-Use Pitcher and Faucet Filters
}

\author{
Jeannie M. Purchase, Rusty Rouillier, Kelsey J. Pieper,* and Marc Edwards*
}

Cite This: Environ. Sci. Technol. Lett. 2021, 8, 155-160

Read Online

ABSTRACT: NSF/ANSI 53 lead-certified point-of-use filters (POUs) have been distributed to consumers in many cities facing lead-in-water crises including Washington, D.C., Flint, MI, Newark, NJ, and University Park, IL. After questions repeatedly arose about POU effectiveness in treating samples with relatively high levels of lead, we examined 10 POU pitcher and faucet filter brands under extreme conditions (e.g., $\leq 200 \%$ of rated capacity, influent lead levels of $\approx 1000 \mu \mathrm{g} / \mathrm{L}$ ). Our tests sought to validate the successful performance documented in some field testing and replicate the underperformance observed in others. While verifying very good performance (i.e., $<10 \mu \mathrm{g} / \mathrm{L}$ effluent lead) across most brands and situations, we encountered a few failures, including leaking units, premature clogging, and a filter with a large hole in the medium. We also synthesized waters with colloidal lead that proved to be especially difficult to treat, as evidenced by $50 \%$ of influent lead passing through some replicate POUs that would have passed NSF/ANSI 53 lead certification testing. While the POUs almost always dramatically reduced consumer lead exposure level, even when operated beyond their rated capacity, this study highlights instances in which treated water exceeded thresholds of 5,10 , and even $15 \mu \mathrm{g} / \mathrm{L}$ lead.

\section{INTRODUCTION}

Hundreds of thousands of point-of-use filters (POUs) have been distributed to consumers during lead-in-water crises to provide safe potable water and protect public health. ${ }^{1-5}$ These POUs were lead-certified under the NSF/ANSI 53 standards to reduce the level of influent lead of standardized challenge waters from 150 to $<10 \mu \mathrm{g} / \mathrm{L}$ until 2019 and to a threshold $<5$ $\mu \mathrm{g} / \mathrm{L}$ effective in 2020. ${ }^{6,7}$ Previous lab and field studies have demonstrated that POUs treating water contaminated with $>1000 \mu \mathrm{g} / \mathrm{L}$ lead usually produced water with $<5 \mu \mathrm{g} / \mathrm{L}$ lead. ${ }^{8-10}$ However, in field validation testing of water samples from Newark, NJ, and elsewhere with $\leq 1670 \mu \mathrm{g} / \mathrm{L}$ lead, POUs had $>15 \mu \mathrm{g} / \mathrm{L}$ effluent lead and in a few cases $>100 \mu \mathrm{g} / \mathrm{L}^{10,11}$ Follow-up investigations in Newark indicated that $97.5 \%$ of properly installed and operated POUs were producing effluent with $<10 \mu \mathrm{g} / \mathrm{L}$ lead, but the sporadic failures nonetheless caused citywide angst, distrust, and a switch to bottled water. $^{10-12}$ To understand why NSF/ANSI 53 lead-certified POUs occasionally produce effluent water with $>10 \mu \mathrm{g} / \mathrm{L}$ lead, we explored POU failure modes due to manufacturing issues, operation beyond rated capacity, and challenge waters with higher particulate lead concentrations.

\section{MATERIALS AND METHODS}

Phase 1: Laboratory Testing of POUs. POU Testing. In April 2018, we reviewed POUs certified by NSF/ANSI 53 for
Point of Use Filter Failures $=$

Manufacturing Issues + Difficult to Treat Particulate Lead Waters
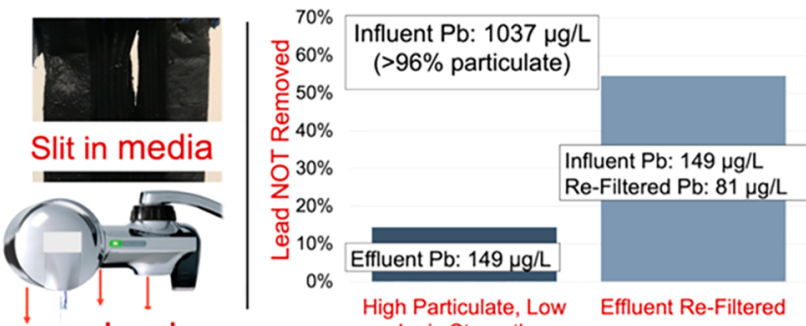
Ionic Strength $\rightarrow$ Step 2 lead removal in the Water Quality Association database and selected 12 POUs with unique filter cartridges (Table S1). All devices were tested in duplicate, except for one brand that was not available for purchase. Testing included four pitcher (brands $\mathrm{A}-\mathrm{C}$ and $\mathrm{L}$ ) and seven faucet POUs (brands $\mathrm{D}-\mathrm{H}, \mathrm{J}$, and $\mathrm{K}$ ). Brand $\mathrm{L}$ filters were excluded from further testing due to what we considered to be an unacceptably low flow rate $[<0.02 \mathrm{~L} / \mathrm{min}$ (Table 1$)]$ during preliminary flow rate testing.

All filter cartridges were conditioned with lead-free challenge waters. Pitcher POUs were soaked for $15 \mathrm{~min}$ and then flushed for $10 \mathrm{~s}$, and faucet POUs were installed and flushed for $5 \mathrm{~min}$. Our performance testing was designed to stress POUs when pushed beyond the NSF/ANSI 53 protocol limits. ${ }^{6}$ Specifically, up to eight $3.8 \mathrm{~L}$ challenge water batches were treated by pitcher filters in an 8-10 h day, with a minimum 30 min rest period between batches (Figure S2). Faucet filters were tested on a cycle of $40 \mathrm{~min}$ on and $40 \mathrm{~min}$ off (section S1). A total of 16 or $17,250 \mathrm{~mL}$ samples were taken at regular intervals up to $200 \%$ of the rated capacity of the POUs (Figure S1). Flow rate,

Received: September 5, 2020

Revised: December 4, 2020

Accepted: December 9, 2020

Published: December 23, 2020 
Table 1. Filter Test Overview

\begin{tabular}{|c|c|c|c|c|c|c|c|}
\hline \multicolumn{8}{|c|}{ Phase 1: Laboratory Testing of POUs } \\
\hline step & water condition & \multicolumn{2}{|c|}{ lead $(\mu \mathrm{g} / \mathrm{L})$} & \multicolumn{2}{|c|}{ procedure } & brands tested & brands removed \\
\hline 1 & tap water & \multicolumn{2}{|l|}{$<\mathrm{MRL}$} & \multicolumn{2}{|c|}{ flow rate trials } & 12 brands $(\mathrm{A}-\mathrm{L})$ & brand L \\
\hline 2 & soluble $\mathrm{Pb}$ & \multicolumn{2}{|c|}{$95.5 \pm 43.6(\mathrm{~F})^{a}$} & \multirow{2}{*}{\multicolumn{2}{|c|}{ tested up to $200 \%$ capacity }} & 11 brands $(\mathrm{A}-\mathrm{K})$ & brands $\mathrm{G}, \mathrm{H}$, and $\mathrm{J}$ \\
\hline & & \multicolumn{2}{|c|}{$149.3 \pm 15.5(\mathrm{P})^{b}$} & & & & \\
\hline 3 & particulate $\mathrm{Pb}$ & \multicolumn{2}{|c|}{$175.5 \pm 34.9(\mathrm{~F})^{a}$} & \multirow{2}{*}{\multicolumn{2}{|c|}{ tested up to $200 \%$ capacity }} & 7 brands $(\mathrm{A}-\mathrm{F}$ and $\mathrm{K})$ & - \\
\hline & & \multicolumn{3}{|c|}{$189.6 \pm 92.1(\mathrm{P})^{b}$} & & & \\
\hline \multicolumn{8}{|c|}{ Phase 2: An In-Depth Examination of Filter Underperformance } \\
\hline step & \multicolumn{2}{|c|}{ water condition } & \multicolumn{2}{|c|}{ lead $(\mu \mathrm{g} / \mathrm{L})$} & volume filtered & effluent sampling & brands tested \\
\hline 1 & particulate $\mathrm{Pb}$ & & & 0.5 & $3.78 \mathrm{~L}$ & $250 \mathrm{~mL}$ & $\mathrm{CD}^{c}$ and new POU \\
\hline 2 & high-particulate $\mathrm{Pb}$ & & 1,01 & 16.8 & $2 \mathrm{~L}$ individual & $250 \mathrm{~mL}$ after each liter & $\mathrm{CD}^{c}$ and new POU \\
\hline 3 & high-particulate $\mathrm{Pb}$ & & 1,01 & 16.8 & $1 \mathrm{~L}$ & $10 \mathrm{~mL}$ & $\mathrm{CD}^{c}$ and new POU \\
\hline 4 & refiltered high-parti & $\mathrm{Pb}$ effluent & & & $1 \mathrm{~L}$ (step 3 effluent) & $1 \mathrm{~L}$ & $\mathrm{CD}^{c}$ and new POU \\
\hline 5 & LIS & & & 54.7 & $1 \mathrm{~L}$ & $1 \mathrm{~L}$ & $\mathrm{CD}^{c}$ and new POU \\
\hline 6 & LIS & & & 54.7 & $1 \mathrm{~L}$ & $10 \mathrm{~mL}$ & $\mathrm{CD}^{c}$ \\
\hline 7 & re-filtered LIS efflu & & & & $1 \mathrm{~L}$ (step 6 effluent) & $1 \mathrm{~L}$ & $\mathrm{CD}^{c}$ \\
\hline
\end{tabular}

conductivity, and ion concentrations were monitored during the testing (section S2). ${ }^{13}$ POU failures were categorized as being related to performance (i.e., $>10 \mu \mathrm{g} / \mathrm{L}$ effluent lead), structural (i.e., loss of POU integrity or function), or clogging (i.e., reduction in flow by $>75 \%$ from its initial rate).

Lead Challenge Waters. "Soluble" and "Particulate" challenge waters were adapted from the NSF/ANSI 53 protocol. ${ }^{6}$ In all cases, the inherent variability of the influent lead water due to settling and losses to the apparatus was accounted for by measuring paired influent and effluent samples. The Soluble water at $\mathrm{pH} 6.5$ with $20 \mathrm{mg} / \mathrm{L}$ alkalinity as calcium carbonate $\left(\mathrm{CaCO}_{3}\right)$ had average influent lead concentrations of $149.3 \pm 15.5$ and $95.5 \pm 43.6 \mu \mathrm{g} / \mathrm{L}(100 \%$ soluble) for pitcher and faucet filter testing, respectively (Table S2). The Particulate water with $100 \mathrm{mg} / \mathrm{L}$ alkalinity as $\mathrm{CaCO}_{3}$ at $\mathrm{pH} 8.5 \mathrm{had}$ an average influent lead concentration of 189.6 $\pm 92.1 \mu \mathrm{g} / \mathrm{L}$ (36\% particulate) for pitcher filters and $175.5 \pm$ $34.9 \mu \mathrm{g} / \mathrm{L}$ (30\% particulate) for faucet filters (Table S2). Particle size distributions were operationally defined by filtration through $0.1,0.45,1.2$, or $5 \mu \mathrm{m}$ pore size filters. We deviated from the NSF/ANSI 53 protocol during preparation of Particulate water by purposefully shaking the oversaturated lead solution instead of stirring it (section S3), which created a higher fraction of $1.2-5 \mu \mathrm{m}$ size particles predicted to have a lower removal efficiency according to granular media filtration theory (section S3)., 14

Phase 2: An In-Depth Examination of Filter Underperformance. Brand A pitcher filters with granulated activated carbon, cation, and anion exchange resin exhibited the best removal throughout phase 1, with effluent lead levels always being $<2.7 \mu \mathrm{g} / \mathrm{L}$. Brand A POUs were distributed in a city, masked herein for confidentiality, that was experiencing high water lead levels. During a field investigation with consumer tap samples with lead levels of $\leq 706 \mu \mathrm{g} / \mathrm{L}$, newly opened brand A filters had effluent lead levels as high as 122 $\mu \mathrm{g} / \mathrm{L}$. Despite the very significant reduction of influent lead levels in all tested conditions, samples with effluent lead levels of $>15 \mu \mathrm{g} / \mathrm{L}$ are perceived as POU underperformance by many stakeholders as was the case in Newark, NJ.

Further analysis of these field samples determined that the new POUs had completely removed soluble anions and cations such as $\mathrm{Na}^{+}, \mathrm{Ca}^{2+}$, and $\mathrm{Cl}^{-}$but were not removing all of the $\mathrm{Pb}$ and $\mathrm{Sn}$, which tended to be almost entirely particulate in this water. We then used a sequence of challenge waters to better understand the nature of the brand A filter underperformance in the laboratory. Two of the new field-tested communitydeployed (CD) POUs were lab tested alongside two newly purchased POUs of the same brand (brand A). By the end of the study, all filters tested had treated at $<52 \%$ of their rated capacity.

Challenge Waters. The highest influent lead levels in the Flint, MI, and Newark, NJ, field studies were 4080 and 1680 $\mu \mathrm{g} / \mathrm{L}$, respectively, and virtually none of this lead was soluble. ${ }^{5,10,11}$ Samples with $>1000 \mu \mathrm{g} / \mathrm{L}$ lead inevitably become a focal point of media attention and filter performance testing. ${ }^{5,10,11,15,16}$ In this testing phase, the POUs were exposed to the Particulate water and two newly created particulate challenge waters (Table S2). The "High-Particulate" water had $1000 \mu \mathrm{g} / \mathrm{L}$ of suspended lead phosphate ( $>99.9 \%$ particulate), with a $\mathrm{pH}$ of 8.5 and an alkalinity of $100 \mathrm{mg} / \mathrm{L}$ as $\mathrm{CaCO}_{3}$. The "Low-Ionic Strength" (LIS) water was the same as HighParticulate water, but without the sodium bicarbonate, magnesium sulfate, or calcium chloride (Table S2). The excess of orthophosphate $(27 \mathrm{mg} / \mathrm{L}$ as $\mathrm{P}$ ) added to these waters caused the soluble lead level to drop below $6 \%$ of the total lead after $1 \mathrm{~h}$, compared to $\approx 20 \%$ soluble lead if a more typical 1 $\mathrm{mg} / \mathrm{L}$ as $\mathrm{P}$ dose of orthophosphate was used. The larger dose of phosphate was used because the fresh lead precipitates had the exact same zeta potential of $-21 \mathrm{mV}$ as those formed at the $1 \mathrm{mg} / \mathrm{L}$ dose, and it also created a broader and more even particle size distribution (Figure S3).

POU Filter Testing Series. The POUs filtered batches of challenge waters in a series of seven steps (Table 1): step 1, 3.8 $\mathrm{L}$ of Particulate water; step 2, two individual $1 \mathrm{~L}$ batches of High-Particulate water; step 3, 1 L of High-Particulate water, with effluent collected; step 4, refiltering the step 3 effluent; step 5, 1 L of LIS water; step 6, 1 L of LIS water, with effluent collected; step 7, refiltering the step 6 effluent as detailed in Table 1.

\section{RESULTS AND DISCUSSION}

Phase 1: Overall Testing Summary. POUs Removed Dissolved Lead. Nine of the 10 POU brands reduced the influent lead level to below the NSF/ANSI 53 certification 


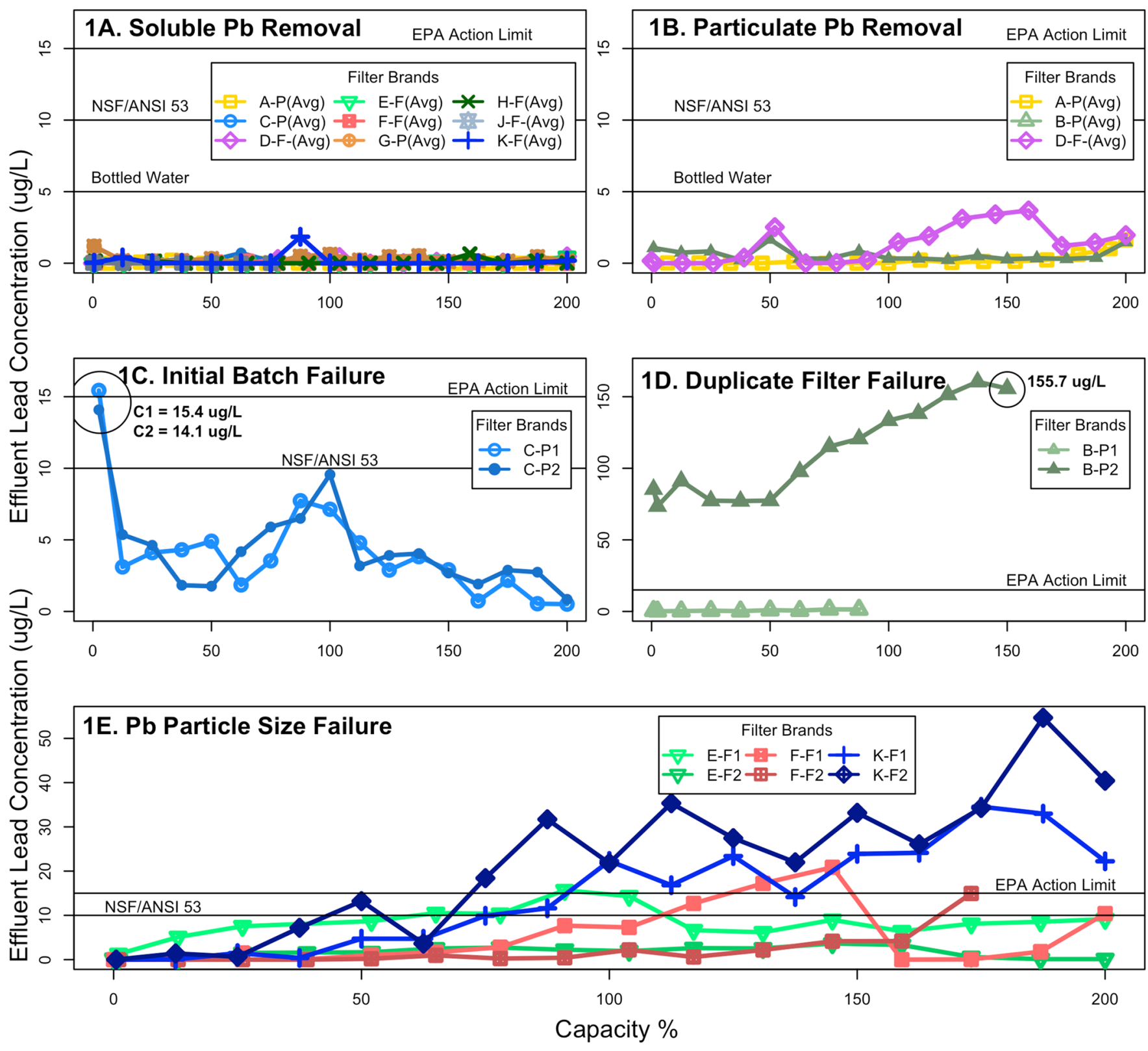

Figure 1. Effluent lead concentration vs filter capacity. (A) Average effluent lead levels of nine brands for soluble Pb Challenge. (B) Average lead levels of three brands for Particulate Pb Challenge. (C) Elevated lead levels in the first sample for a brand C pitcher filter. (D) Brand B pitcher filter failures for soluble $\mathrm{Pb}$ Challenge, for both duplicates. (E) Six faucet filters across three brands, with effluent lead levels of $>10 \mu \mathrm{g} / \mathrm{L}$ for the Particulate $\mathrm{Pb}$ Challenge.

thresholds of 5 and $10 \mu \mathrm{g} / \mathrm{L}$ for the Soluble challenge water when tested at $\leq 200 \%$ capacity (Figure $1 \mathrm{~A}$ and Table S1). The lead levels of all 288 effluent samples from these 9 POU brands were $<3.7 \mu \mathrm{g} / \mathrm{L}$, and the average lead removal efficiency was $99.87 \%$. One brand B duplicate (discussed in Structural Problems with POUs) failed to consistently reduce $<10 \mu \mathrm{g} / \mathrm{L}$ lead (Figure 1D).

POUs Struggled to Remove Particulate Lead. The lead removal performance for the Particulate water was more variable. Only 3 of 7 filter brands [A, B, and D (Figure 1B and Table S1)] all had effluent lead levels of $<10 \mu \mathrm{g} / \mathrm{L}$ for $\leq 200 \%$ capacity, with 99 of 100 samples with effluent lead $<5 \mu \mathrm{g} / \mathrm{L}$ and an average lead level of $0.3-1.3 \mu \mathrm{g} / \mathrm{L}$ for each brand. Brand C (pitcher) had a high lead level in the first effluent batch for both duplicates [14.6 and $15.4 \mu \mathrm{g} / \mathrm{L}$ (Figure 1C)], but after that, effluent levels were $<10 \mu \mathrm{g} / \mathrm{L}$ and $76 \%$ of the 34 samples had levels of $<5 \mu \mathrm{g} / \mathrm{L}$. Brands E, F, and $\mathrm{K}$ (faucet) had at least one sample with an effluent lead level $>10 \mu \mathrm{g} / \mathrm{L}$ (Figure 1E).

The lead levels for one duplicate filter tested of brand E, EF2, remained below $5 \mu \mathrm{g} / \mathrm{L}$ at all points $\leq 200 \%$ capacity, while the levels of the other duplicates E-F1 exceeded $10 \mu \mathrm{g} / \mathrm{L}$ between $65 \%$ and $104 \%$ of the rated capacity. Both brand $\mathrm{F}$ duplicates produced water with lead levels exceeding the limit of $15 \mu \mathrm{g} / \mathrm{L}$ at $\geq 173 \%$ capacity. The brand $\mathrm{K}$ duplicate filters had the highest effluent lead levels for treating Particulate water, with values of $\leq 34.6$ and $\leq 54.7 \mu \mathrm{g} / \mathrm{L}$ for the duplicates. The lead levels for both duplicate filters exceeded $10 \mu \mathrm{g} / \mathrm{L}$ upon reaching $50 \%$ and $88 \%$ capacity. These failures suggest that our efforts to make particulate lead sizes that were more difficult to treat than those of standard NSF/ANSI 53 testing may have been successful because effluent lead levels must 
remain below $10 \mu \mathrm{g} / \mathrm{L}$ for certification when exposed to the NSF 53 version of this water.

Structural Problems with POUs. Several POU brands experienced structural problems during testing. Brand L duplicates required $>200 \mathrm{~min}$ to filter $3.8 \mathrm{~L}(<0.02 \mathrm{~L} / \mathrm{min})$, which was considered an unrealistically low initial flow rate, compared to the average of $44 \mathrm{~min}$ required for pitcher brands $\mathrm{A}-\mathrm{C}$ to filter the same volume. When faucet filtering Soluble water, Brand J had an extremely low flow rate of $0.58 \mathrm{~L} / \mathrm{min}$ at only $75 \%$ capacity, a $30 \%$ reduction from its initial flow rate and less than half the average flow rate of other faucet filter brands for this condition $[1.24 \mathrm{~L} / \mathrm{min}$ (Table S5)]. The filter housing of brands $\mathrm{G}$ and $\mathrm{H}$ leaked from multiple points when attached to the faucet (Figure S4), which required replacement prior to Soluble water testing.

The flow rate and removal efficiency of brand $\mathrm{B}$ deviated markedly between duplicates (Figure 1D). B-P1 had all effluent lead levels of $<1.5 \mu \mathrm{g} / \mathrm{L}$ (98.9-100\% reduction) but clogged at $81 \%$ rated capacity, as the flow rate dropped from 189.3 to $47.3 \mathrm{~mL} / \mathrm{min}$ (Table S4). In contrast, the flow rate of B-P2 increased with time and only removed $5-48 \%$ of the lead. At the end of the experiment, we carefully cut away the outer wall of both filter cartridges to better understand the differing trends, revealing a large hole through the medium of B-P2 but not that of B-P1 (Figure S5). Consistent with our discovery, online consumer reviews of this brand sometimes reported very fast flow rates co-occurring with inadequate removal of color, taste, and odors, indicating our results were not isolated. There are inconsistencies in POU manufacturing and quality control, which may not be detected in the standard NSF/ANSI 53 certification testing of one or two devices that are selected by the manufacturer.

Public Health Impact of Exceeding the Rated POU Capacity or NSF/ANSI 53 Influent Lead Levels. Concerns have been expressed about potential dangers to consumers if POUs are used beyond their rated capacity. Some of these concerns are based on prior experiences with POU treatment of arsenic with anion exchange media. Exceeding the capacity can cause the level of arsenic in treated water to be higher than the level of arsenic in the influent due to a chromatographic effect from sulfate competition. ${ }^{17}$ While POU performance for lead did deteriorate with increased use as expected, a relatively high percentage of lead removal $(>71 \%)$ was almost always maintained even when used to $<200 \%$ of the rated capacity. There was no evidence of chromatographic peaking, as expected given different mechanisms of removal for lead versus arsenic. Likewise, treating water batches more frequently or with lead levels much higher than those recommended by manufacturers in this work still resulted in relatively high lead removal efficiencies.

Phase 2: An In-Depth Examination of Filter Underperformance. All POUs Removed Particulate Lead. When exposed to our Particulate water (average influent lead level of $179.4 \pm 0.5 \mu \mathrm{g} / \mathrm{L}$ ), all four POUs had effluent lead levels $<1$ $\mu \mathrm{g} / \mathrm{L}$, which proved that all of the brand A filters would likely meet certification standards (Table S7).

$C D$ Filters Struggled with High-Particulate Water. When the High-Particulate water (average influent level of $1011.5 \pm$ $16.8 \mu \mathrm{g} / \mathrm{L}$ ) was tested, the new POU duplicates still met the $<10 \mu \mathrm{g} / \mathrm{L}$ threshold while the CD POUs exceeded $10 \mu \mathrm{g} / \mathrm{L}$ with effluent lead levels of 42.1-66.6 $\mu \mathrm{g} / \mathrm{L}$ (i.e., 10 times higher than those of the new POUs) (Table S7). Throughout all of these studies, all soluble ions were completely removed by all of the filters, including $\mathrm{Na}^{+}$and $\mathrm{Cl}^{-}$, which confirms that the filter medium's capacity was never an issue and supports our hypothesis that lead particles or colloids were somehow passing through the filter.

To examine a hypothesis that particulates not removed by the POUs on the first pass through the filter represented a fraction of particulate lead that was somehow more difficult to remove, the effluents from the High-Particulate water were refiltered by each POU. After the first pass, CD1 had an effluent lead level of $26.6 \mu \mathrm{g} / \mathrm{L}$, and when the sample was refiltered, the lead level decreased to only $15.5 \mu \mathrm{g} / \mathrm{L}$. The duplicate CD2 had a lead level of $63.9 \mu \mathrm{g} / \mathrm{L}$ in the effluent first pass, and when the sample was refiltered, it was decreased to $40.3 \mu \mathrm{g} / \mathrm{L}$. Thus, the removal efficiency decreased from $94 \%$ to $97 \%$ on the first pass down to $37-42 \%$ on the second pass for the duplicate tests, confirming that some particles in the influent had a lower removal efficiency by filtration. A similar reduction was seen in the new POUs. When the first-pass effluents with levels of $5.3-5.8 \mu \mathrm{g} / \mathrm{L}$ were refiltered, the effluent lead levels were $1.6 \mu \mathrm{g} / \mathrm{L}$. The removal efficiency of $99.4-99.7 \%$ from the first pass had been reduced to $70-72 \%$ in the second pass through these devices.

All POUs Struggled to Treat LIS Water. The Newark, NJ, water had relatively low ionic strength and hardness values, expected to reduce particle removal efficiencies by granular media due to increased electrostatic repulsive forces between particles and the filter medium. ${ }^{11,18}$ Consistent with this expectation, the effluent lead level was $>15 \mu \mathrm{g} / \mathrm{L}$ for all four POUs when exposed to the LIS water with an average influent lead level of $991.4 \pm 54.7 \mu \mathrm{g} / \mathrm{L}$. Specifically, the new duplicate POUs had effluent lead levels of 19 and $29 \mu \mathrm{g} / \mathrm{L}$ (97-98\% removal), whereas the CD filters had effluent lead levels of 123 and $181 \mu \mathrm{g} / \mathrm{L}(81-87 \%$ removal $)$. The latter result was in the range of the worst performance encountered in the CD field testing, in which the influent lead level was $706 \mu \mathrm{g} / \mathrm{L}$ and the effluent lead level was $122 \mu \mathrm{g} / \mathrm{L}$ (only $84 \%$ removal). In other words, the batch of CD filters had effluent lead levels 4.2-9.5 times higher than those of the new batch of POUs upon treatment of this water.

When the LIS water was retested to confirm the results of the CD POUs, the removal rates were again 86-90\% (effluent levels of $102-148 \mu \mathrm{g} / \mathrm{L}$ ). While the LIS water effluent was refiltered, the removal rate for CD1 was only $48.4 \%$ (from 102 to $53 \mu \mathrm{g} / \mathrm{L}$ ) and $45.4 \%$ for CD2 (from 148 to $81 \mu \mathrm{g} / \mathrm{L}$ ). Overall, this work demonstrates that there can be fractions of particulate lead in samples that are very difficult to remove. ${ }^{14}$

It was hypothesized that particle size and surface charge, as controlled by water chemistry, partly contributed to the low removal efficiency, as expected on the basis of filtration trajectory and sieving theory. ${ }^{14,18}$ Filter size fractionation of a representative LIS CD filter effluent sample indicated that approximately half of the particles evading removal in the LIS water were $>5 \mu \mathrm{m}$ or between 1.2 and $5 \mu \mathrm{m}$ (Figure 2). These results are not inconsistent with findings of Lytle et al., ${ }^{11}$ who found that the vast majority of lead evading POU removal in three Newark homes was removed by a $0.2 \mu \mathrm{m}$ pore size filter. These authors did not further characterize the effective size of agglomerates in the influent or effluent water using larger filter pore sizes.

It is also clear that manufacturing deviations within a brand (i.e., duplicate $\mathrm{CD}$ filters vs new duplicate filters) can produce marked variations in performance for difficult-to-treat waters that are not detectable in the NSF/ANSI 53 test water with 


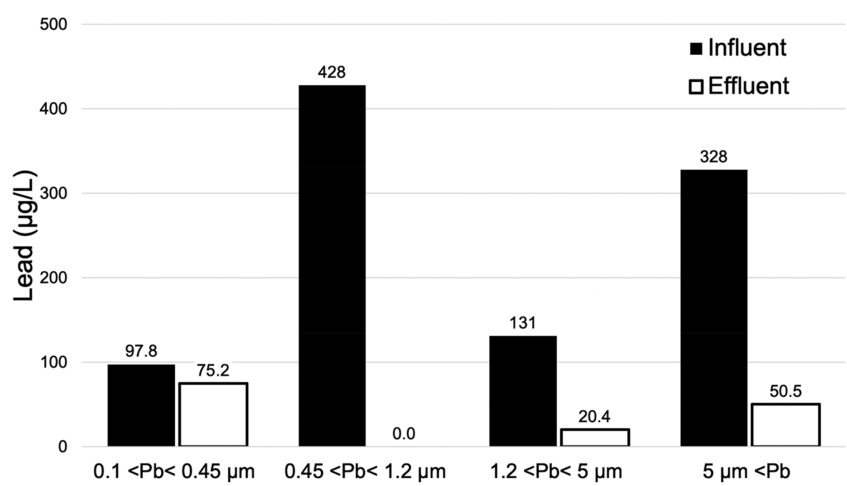

Figure 2. Filtration size distribution for influent and effluent lead for a representative use of $\mathrm{CD} 2$, specifically step 7 , Table S7.

only $30 \%$ particulate lead. A forensic analysis of these four filters upon completion of the study did not reveal any noteworthy differences between the two different batches (e.g., hole in the media like brand B-P2). However, a compilation of initial flow rates for 28 of these filters over our study revealed a wide range from 62 to $171 \mathrm{~mL} / \mathrm{min}$, with an average of 130 $\mathrm{mL} / \mathrm{min}$ and a standard deviation $30 \mathrm{~mL} / \mathrm{min}$ (Table S8). The two CD filters did have higher than average flow rates of 152 and $157 \mathrm{~mL} / \mathrm{min}$ when first received in our lab. While we did not track flow rates systematically throughout the case study and cannot definitively attribute differences in lead removal performance to this factor, the flow rate variability does reveal manufacturing deviations that could sometimes affect field performance.

Overall, while POUs usually provide important consumer protection in water lead contamination events and water crises, they occasionally have issues that can cause effluent lead levels to exceed desired public health thresholds. The NSF/ANSI 53 protocol committee should consider challenge waters with a higher particulate lead percentage. The current particulate lead challenge water with only $30 \%$ particulates does not reflect conditions with $\leq 100 \%$ particulate lead encountered in recent water crises. Considering that no safety device is foolproof or $100 \%$ effective, it is also important to manage performance expectations for these devices with regulators, disaster relief organizations, media, building managers, and consumers. ${ }^{12,16,19}$ Finally, while the use of POUs beyond rated capacities did not ever cause the effluent lead levels to exceed the influent lead levels, the importance of properly maintaining the filters should continue to be emphasized.

\section{ASSOCIATED CONTENT}

\section{SI Supporting Information}

The Supporting Information is available free of charge at https://pubs.acs.org/doi/10.1021/acs.estlett.0c00709.

Three sections of experimental details, eight tables, and five figures (PDF)

\section{AUTHOR INFORMATION}

\section{Corresponding Authors}

Marc Edwards - The Charles Edward Via, Jr. Department of Civil and Environmental Engineering, Virginia Tech, Blacksburg, Virginia 24061, United States; (1) orcid.org/ 0000-0002-1889-1193; Email: edwardsm@vt.edu

Kelsey J. Pieper - Department of Civil and Environmental Engineering, Northeastern University, Boston, Massachusetts
02115, United States; 이이이.org/0000-0002-0273-6527; Email: k.pieper@northeastern.edu

\section{Authors}

Jeannie M. Purchase - The Charles Edward Via, Jr. Department of Civil and Environmental Engineering, Virginia Tech, Blacksburg, Virginia 24061, United States

Rusty Rouillier - The Charles Edward Via, Jr. Department of Civil and Environmental Engineering, Virginia Tech, Blacksburg, Virginia 24061, United States

Complete contact information is available at: https://pubs.acs.org/10.1021/acs.estlett.0c00709

\section{Notes}

The authors declare the following competing financial interest(s): M.E. has consulted on a project with the Water Research Foundation reviewing performance data on POU underperformance in a large U.S. city.

\section{ACKNOWLEDGMENTS}

This research was supported by Housing and Urban Development (HUD) Healthy Home Technical Studies Grant VAHHU0036-17. Undergraduate students Joseph Hector, Ailene Edwards, Rebekah Broyles, Sarah Loomis, Isabella Lerer, Jesika McDaniel, Leila Husain, Paighton Vanzant, Natalie Stone, and Abby Simonpietri assisted with the two years of laboratory work presented herein.

\section{REFERENCES}

(1) Agnvall, E. Filters That Get the Lead Out. Washington Post. https://www.washingtonpost.com/archive/lifestyle/wellness/2004/ 03/30/filters-that-get-the-lead-out/f5a89414-b88f-4da7-8836dfb98d20e197/ (accessed 2020-08-26).

(2) MDEQ. Summary of Flint Response Activities; Flint, MI, 2016.

(3) City Continues Vigorous Campaign To Distribute Filter Replacement Cartridges To Residents. https://www.newarknj.gov/ news / city-continues-vigorous-campaign-to-distribute-filterreplacement-cartridges-to-residents (accessed 2020-08-26).

(4) Koeske, Z. More than 6 months after elevated lead levels were discovered in University Park, affected residents still don't know when they'll be able to consume water without restrictions. Chicago Tribune. https://www.chicagotribune.com/suburbs/daily-southtown/ct-stau n i versity - park-a qua - s t - $0102-20191231$. q7qrk24ydbhslgjgmsncjmd7uy-story.html (accessed 2020-08-26).

(5) Bosscher, V.; Lytle, D. A.; Schock, M. R.; Porter, A.; Del Toral, M. POU Water Filters Effectively Reduce Lead in Drinking Water: A Demonstration Field Study in Flint, Michigan. J. Environ. Sci. Health, Part A: Toxic/Hazard. Subst. Environ. Eng. 2019, 54 (5), 484-493.

(6) NSF International. NSF/ANSI 53-2015: Drinking Water Treatment Units - Health Effects. Ann Arbor, MI, 2015.

(7) NSF International. NSF/ANSI 53-2019: Drinking Water Treatment Units - Health Effects. Ann Arbor, MI, 2019.

(8) Deshommes, E.; Zhang, Y.; Gendron, K.; Sauvé, S.; Edwards, M.; Nour, S.; Prévost, M. Lead Removal from Tap Water Using POU Devices. J. - Am. Water Works Assoc. 2010, 102 (10), 91-105.

(9) Pan, W.; Johnson, E. R.; Giammar, D. E. Accumulation on and Extraction of Lead from Point-of-Use Filters for Evaluating Lead Exposure from Drinking Water. Environ. Sci. Water Res. Technol. 2020, 6, 2734.

(10) CDM Smith. City of Newark Point-of-Use Filter Study (August-September 2019) Filter Results Report - Final. Newark, NJ, 2019.

(11) Lytle, D. A.; Schock, M. R.; Formal, C.; Bennett-Stamper, C.; Harmon, S.; Nadagouda, M. N.; Williams, D.; DeSantis, M. K.; Tully, J.; Pham, M. Lead Particle Size Fractionation and Identification in 
Newark, New Jersey's Drinking Water. Environ. Sci. Technol. 2020, 54, 13672.

(12) Ingber, S. Newark's Drinking Water Problem: Lead and Unreliable Filters. https://www.npr.org/2019/08/13/750806632/ newarks-drinking-water-problem-lead-and-unreliable-filters (accessed 2020-08-26).

(13) Standard Methods for the Examination of Water and Wastewater, 23rd ed.; American Public Health Association, American Water Works Association, and Water Environment Federation: Washington, DC, 2017.

(14) Elimelech, M.; Gregory, J.; Jia, X. Predictions of Filter Performance. In Particle Deposition and Aggregation: Measurement, Modelling, and Simulation; Butterworth-Heinemann, 2013; pp 354359.

(15) Mantha, A.; Tang, M.; Pieper, K. J.; Parks, J. L.; Edwards, M. A. Tracking Reduction of Water Lead Levels in Two Homes during the Flint Federal Emergency. Water Res. X 2020, 7, 100047.

(16) Pieper, K. J.; Tang, M.; Edwards, M. A. Flint Water Crisis Caused by Interrupted Corrosion Control: Investigating "Ground Zero” Home. Environ. Sci. Technol. 2017, 51 (4), 2007-2014.

(17) Chen, H.; Frey, M. M.; Clifford, D.; McNeill, L. S.; Edwards, M. Arsenic Treatment Considerations. J. - Am. Water Works Assoc. 1999, 91 (3), 74-85.

(18) Ryan, J. N.; Elimelech, M. Colloid Mobilization and Transport in Groundwater. Colloids Surf., A 1996, 107, 1-56.

(19) Roy, S.; Edwards, M. A. Citizen Science during the Flint, Michigan Federal Water Emergency: Ethical Dilemmas and Lessons Learned. Citizen Science: Theory and Practice 2019, DOI: 10.5334/ cstp.264. 